تأثير اثعة كاما في بعض ادوار حشرة ثاقبة الحبوب الصغرى

Rhyzopertha dominica (Fab)

عماد /حمد محمود ***

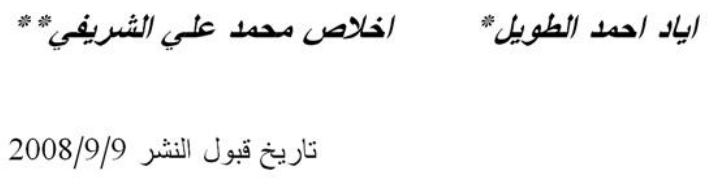

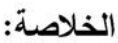

درس تأثير اشعة كاما في تطور بعض ادوار حشرة ثاقبة الحبــوب الصــغرى المشــعة

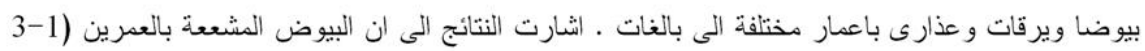

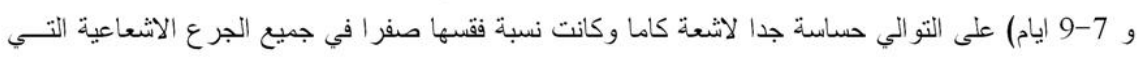
عرضت لها ـ كما اوضحت النتائج ان الدور اليرقي بطورية الاول والاخير اختلافا بحساسيتهما لاشعة كاما ،

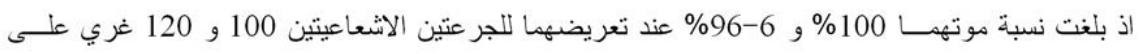

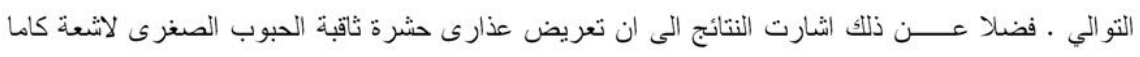

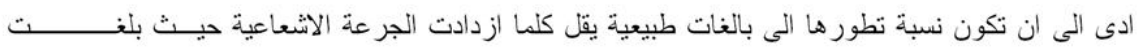

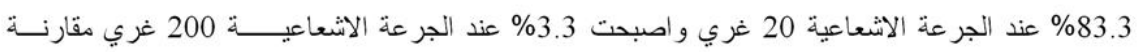

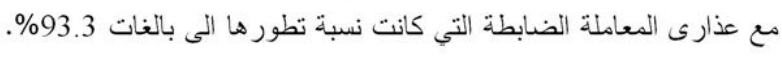
كلمات مفتاحية: اشعة كاما، ثاقبة الحبوب الصغرى، حياتية الحثرة. خزن الحبوب هي حشرة ثاقبة الحبــوب

المقدمة

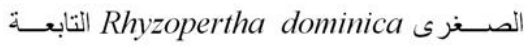

لعائلة Bostrichidae من رتبة غمدية الاجنحــة [1و Coleoptera

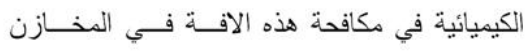

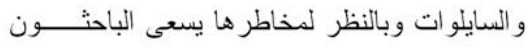

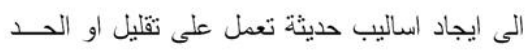

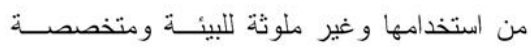

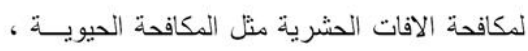

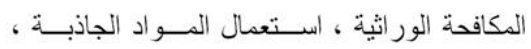

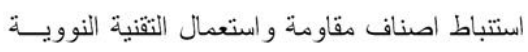
تعد الحبوب محصول النباتات التي تعود الى العائلة العشبية المسماة بالعائلة النجيلية و التــي تلتي

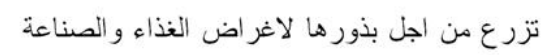

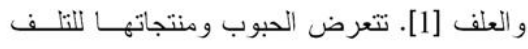

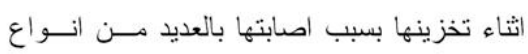

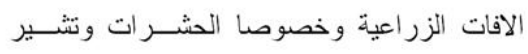

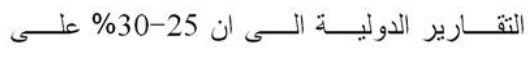

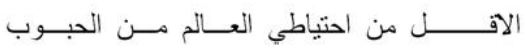

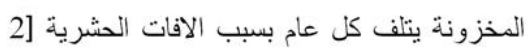

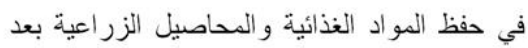
ان احدى الافات التي تسبب خسائر كبيــرة اثتـــاء

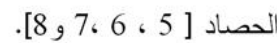

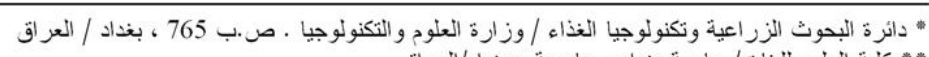

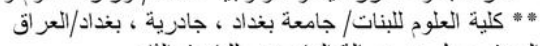


تاثير اشعة كاما في نسبة فقس البيض لحشــرة ثاقبة الحبوب الصغرى.

هيئـــت عثــــرة اطبــــاق بلاســـتيكية

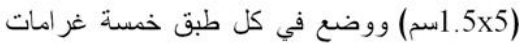

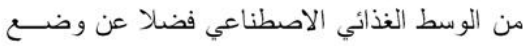

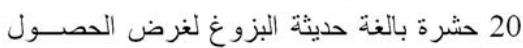

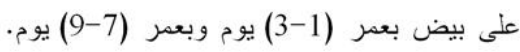

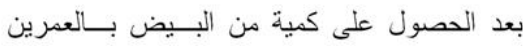

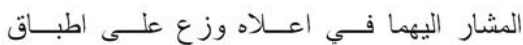
بلاستيكية بو اقع عشرة بيضات لكل طبق وبو اقــع

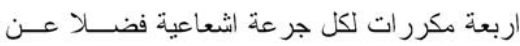

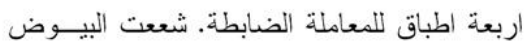
لكلا العمرين بجر ع اشعاعية تر اوحت بين 10 و 60 غري وبزيادة 5 غري باستعمال خلية كاما -

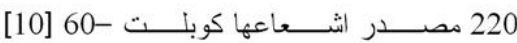
و الموجــودة فــي مركــز البحـــوث الزر اعيـــة و البيولوجية /منظمة الطاقة الذرية ســابقا-وزارة

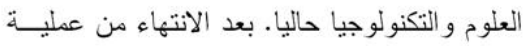

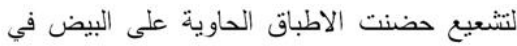

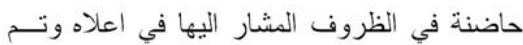
مر اقبة وفحص البيض يوميا لحساب نسبة فقسه.

تاثير اشعة كاما في تطور يرقات وعذارى حشرة

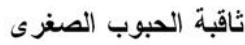

عزل كل من الطور اليرقي الاول (17-

20) يوما و الطور اليرقي الاخير (45-50) يوما و العذارى بعمر (1-3) يوم من العشبرة السكانية

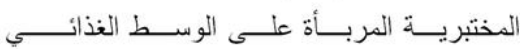
الاصطناعي , وزعت اليرقات بو اقع عشرة يرقات

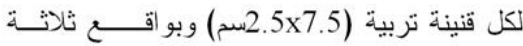
مكررات لكل جر عة اشعاعية و التتي تر اوحت بين

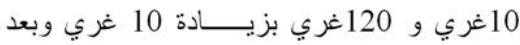
اتمام عملية التشعيع اضيف لكل قنينة تربية خمسة

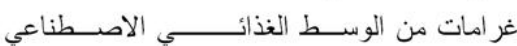

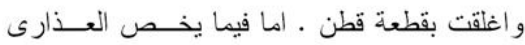

يهذف هذا البحث الى دراسة الحساسـية

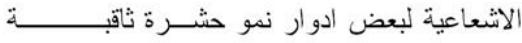

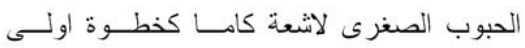

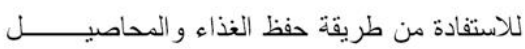

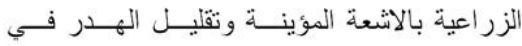

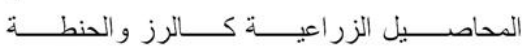

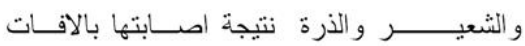

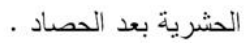

المواد وطر ائق العمل: - ائق

تهيئة وادامة العشيرة السكانية المختبرية لحشرة

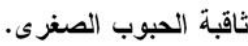

تم الحصول على مئتان وخمسون غر اما

من بذور الثثلب المصاب بحشرة ثاقبــة الحبــوب

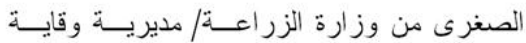
المزروعات - شعبة الحبوب المخزونة في عـام الزراع 2002 و اكد نتخيص الحشرة من قبــل متحــف فئس التاريخ الطبيعي / جامعة بغداد على انها حشـــرة ثاقبة الحبوب الصغرى ـ لاكثار العشيرة السكانية

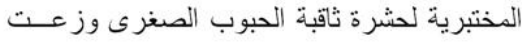
هذه الكمية من بذور الثلب المصــاب بالتشــاوي داقية

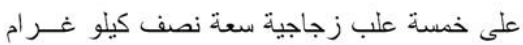
و اضيف لكل علبة مئتي غر ام من بـذذور الثـــلب

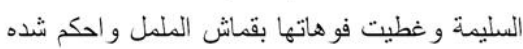

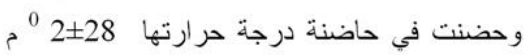

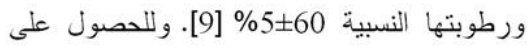

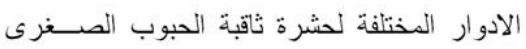

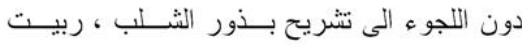
الحشرة على وسط غذائي اصطناعي مكون مسن لـن مسحوق الذرة ومسحوق بذور الثلب والخميــرة بنسبة 2:4:4 [9]. 
(جدول 1) ـ ان هذه النتيجة يمكن تفسير ها علـى

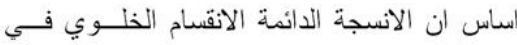

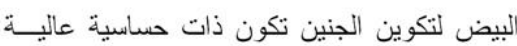

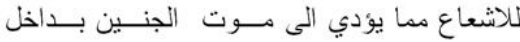

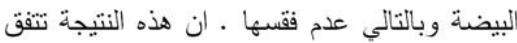
مع ما وجده Tilton وجماعته [12] عند در استهم تاثير اثعة كاما في نسبة فقس بيض الحشرة نفسها

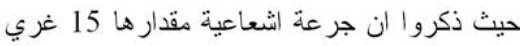

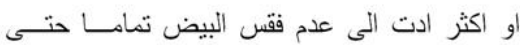
عندما فحص بعد شهر من النشعيع · كما وتتفق هذه النتيجة مع نتائج باحثون

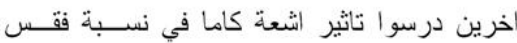
C. maculatus بيض خنفساء اللوبياء الجنوبيـة

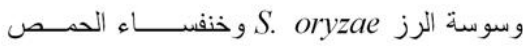
.[15, 14 ، 13] C. chinensis

تأثير اشعة كاما في يرقات حشرة ثاقبة الحبــوب

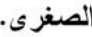

تشير نتائج الجدولين 2 و 3 الى ان نسبة موت برقات الطورين اليـــقيين الاول و الاخيــر

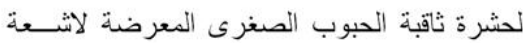
كاما تتناسب طرديا مع زيادة الجر عة الاثــعاعية حيث ازدادت معنويا P> 0.05 حتى وصلت الى

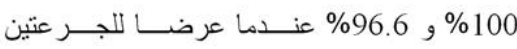
الاثعاعيتين 100 و 120 غري على التو التي. وقد

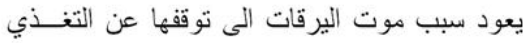

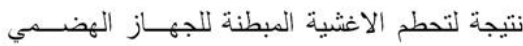
وخصوصـا الانابيب الثشعرية التي تقــوم بعمليــة امتصاص الغذاء كما بين ذلك Diop وجماعتـــ

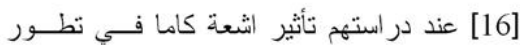

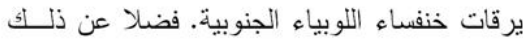

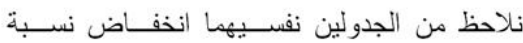

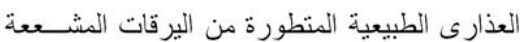
حيث وصلت هذه النسبة الى 3.4\% عند الجرعة

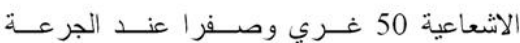

فوضعت عثــرة عـذراوات فـي كــل قنينــة

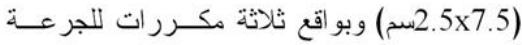

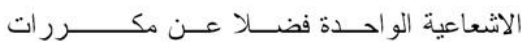

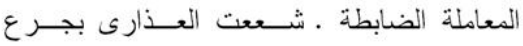
اثـــعاعية تر اوحسـت بــين 20 غـــري و 200

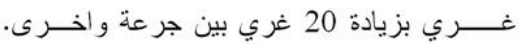

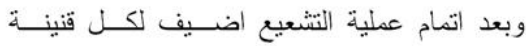

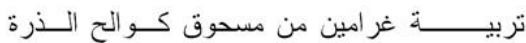

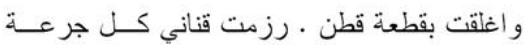
اشعاعيــــة ولكل عمر يرقي وللعذارى وللمعاملة ورئة

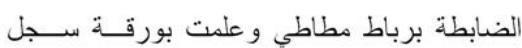

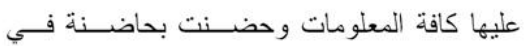
الظروف المشار اليها اعلاه ، وتم متابعة تطـــور طـــــوري اليرقات و العذارى الّى بالغات.

\section{التحليل الاحصائي}

حللت بيانات تأثير اشعة كاما في بيوض الثاسي

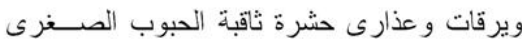

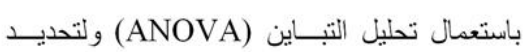
معنوية الفروق بين المتوسطات استعمل اختبــار د دنكن متعدد الحدود عند مستوى الاحتمال 0.05 > بأعتماد البرنامج الاحصــائي الجـاهز (11) . SAS

\section{النتائج و المناقثنة}

تأثير اشعة كاما في نسبة فقس البيض لحشــرة

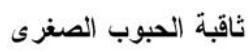

دت عملية تشعيع بيض حشــرة ثاقبــة

الحبوب الصغرى بمرحليته العمــريتين المبكـــرة

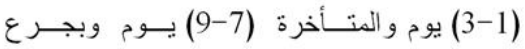
اشعاعية تراوحت بين 10 غرب و 60 غري الى ودي عدم فقسه تماما اي بمعنى ان نسبة الفقس كانــت

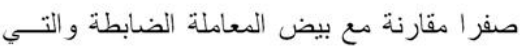
تر اوحت نسبة فقسـه بـين 76.6\% و 83.3\% 
النسبة بزيادة الجرعة الاثــعاعية حيــث كانــت

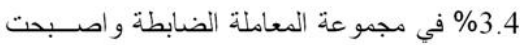
\%6.7 عند الجر عة الاشعاعية 200 غري و ادت نسبة الموت العالية للعذارى المشععة الى حصول

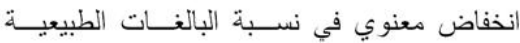

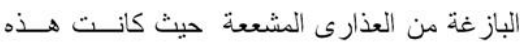
النسبة 93.3\% لمجموعــة المعاملــة الضــابطة و اصبحت 3.3\% عند الجرعة الاثــعاعية 200 غري . كما ونلاحظ من نفس الجــدول ان نسـبة الجنة

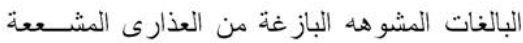

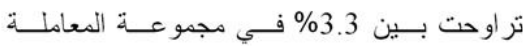

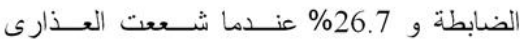
بجر عة اشعاعية مقدار ها 120 غري بينمــا فـي الجرع الاشعاعية التي هي اعلى من 120 غـــري

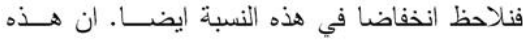

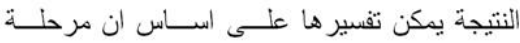

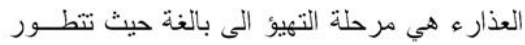

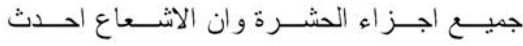

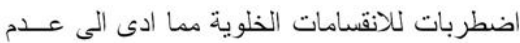

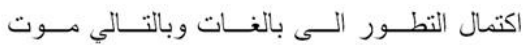
الحشر ات داخل اغلفــة العــذارى وكمـــــــــار Davies

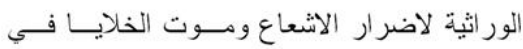
الحشر ات و الكائنات الحية الاخرى وكـــللك مـــع احمد [5] لدى دراسـته الحساســيه الاثــعاعية للادو ار المختلفة للحشر ات لاشعة كاما.

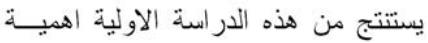

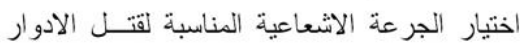
و الاعمار المختلفة لحشرة ثاقبة الحبوب الصغرى ضمن برنامج متكامل لحفظ الحبوب بصورة عامة لدمة و الرز بصورة خاصة باستعمال نقنية حفظ الغذاء

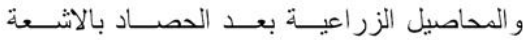
المؤينة.
الاشعاعية 60 غري و اكثر عندما شــع الطــور اليرقي الاول (جدول 2) بينما وصلت هذه النسبة الىى 3.3\% عند الجر عة الاثـــاعية 80 غــري وصفر ا عند الجرعة الاشعاعية 90 غري و اكثـر عندما شعع الطور اليرقي الاخير (جدول 3) ـ. اما

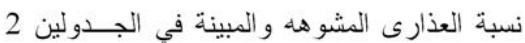

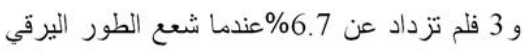

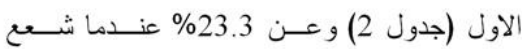

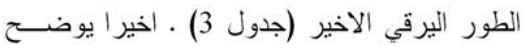
الجدولين نفسيهما ان نسـبـة البالغــات الطبيعيـة الطية

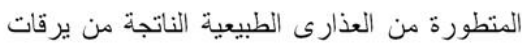

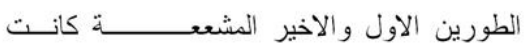
67 و 50\% للجر عيتن الإشعاعيتين 10 و 20

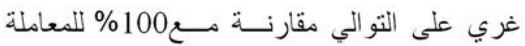
الضابطة عندما شعع الطور اليرقي الاول وكانت

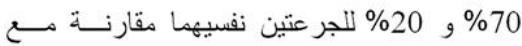

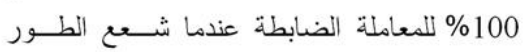
الثيرقي الاخير ـ تنفق نتائج تأثير اشعة كاما فـي

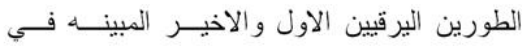

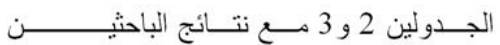

[18] Bagheri , [17] Shokoohian

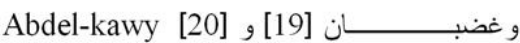
و الجواري [20] عند در استهز ت تأثير اشعة كامــا D. maculatus في تطور يرقات خنفساء الجلود

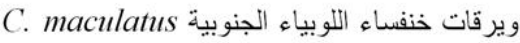

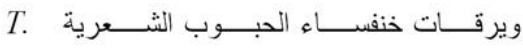
granarium الى بالغات .

تاثير اشعة كاما في عذارى حشرة ثاقبة الحبوب

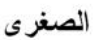

توضح النتائج المبينة فـي جـدول (4)

وجود اختلاف معنوي عنـــد مسـتوى الاحتــــال

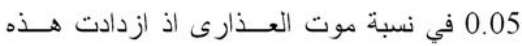


جدول (1) تأثير اشعة كاما في النسبة المئوية لفقس بيض حشرة ثاقبة الحبوب الصغرى .

\begin{tabular}{|c|c|c|}
\hline \multicolumn{2}{|c|}{ نسبة البيض الفاقس } & الجر عة الاشعاعية (غري) \\
\hline (7-9) يوم & (1-1) يوم & \\
\hline $83.3 \mathrm{a}$ & $76.6 \mathrm{a}$ & 0.0 \\
\hline $0.0 \mathrm{~b}$ & $0.0 \mathrm{~b}$ & 10 \\
\hline $0.0 \mathrm{~b}$ & $0.0 \mathrm{~b}$ & 15 \\
\hline $0.0 \mathrm{~b}$ & $0.0 \mathrm{~b}$ & 20 \\
\hline $0.0 \mathrm{~b}$ & $0.0 \mathrm{~b}$ & 25 \\
\hline $0.0 \mathrm{~b}$ & $0.0 \mathrm{~b}$ & 30 \\
\hline $0.0 \mathrm{~b}$ & $0.0 \mathrm{~b}$ & 35 \\
\hline $0.0 \mathrm{~b}$ & $0.0 \mathrm{~b}$ & 40 \\
\hline $0.0 \mathrm{~b}$ & $0.0 \mathrm{~b}$ & 45 \\
\hline $0.0 \mathrm{~b}$ & $0.0 \mathrm{~b}$ & 50 \\
\hline $0.0 \mathrm{~b}$ & $0.0 \mathrm{~b}$ & 55 \\
\hline $0.0 \mathrm{~b}$ & $0.0 \mathrm{~b}$ & 60 \\
\hline
\end{tabular}

جدول (2) تأثير اشعة كاما في تطور الطور اليرقي الاول لحشرة ثاقبة الحبوب الصغرى الى بالغات

\begin{tabular}{|c|c|c|c|c|}
\hline نسبة البالغـات & المعبة العذارى المشو هـ & $\begin{array}{r}\text { المعبة العذارى الطبيعية } \\
\text { القياسية } \\
\text { الانحر اف }\end{array}$ & المعبة موت اليرقات & 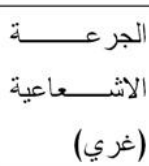 \\
\hline $100 \mathrm{a}$ & $3.6 \pm 13.4 \mathrm{a}$ & $10.3 \pm 65.6 \mathrm{~b}$ & $6.8 \pm 30.0 \mathrm{~d}$ & 0.0 \\
\hline $67 \mathrm{~b}$ & $3.3 \pm 6.6 \mathrm{a}$ & $2.5 \pm 10.4 \mathrm{a}$ & $8.8 \pm 83.0 \mathrm{c}$ & 10 \\
\hline $50 \mathrm{~b}$ & $3.3 \pm 6.6 \mathrm{a}$ & $0.7 \pm 7.4 \mathrm{a}$ & $6.8 \pm 86.6 \mathrm{c}$ & 20 \\
\hline $0 \mathrm{c}$ & $1.6 \pm 3.3 \mathrm{a}$ & $1.3 \pm 3.4 \mathrm{a}$ & $6.7 \pm 93.3 \mathrm{~b}$ & 30 \\
\hline $0 \mathrm{c}$ & $1.0 \pm 3.4 \mathrm{a}$ & $0.0 \pm 0.0 \mathrm{a}$ & $3.3 \pm 96.6 \mathrm{~b}$ & 40 \\
\hline $0 \mathrm{c}$ & $1.6 \pm 3.3 \mathrm{a}$ & $1.0 \pm 3.4 \mathrm{a}$ & $33 \pm 93.3 \mathrm{~b}$ & 50 \\
\hline $0 \mathrm{c}$ & $2.6 \pm 6.7 \mathrm{a}$ & $0.0 \pm 0.0 \mathrm{a}$ & $3.5 \pm 93.3 \mathrm{~b}$ & 60 \\
\hline $0 \mathrm{c}$ & $3.3 \pm 6.7 \mathrm{a}$ & $0.0 \pm 0.0 \mathrm{a}$ & $3.5 \pm 93.3 \mathrm{~b}$ & 70 \\
\hline $0 \mathrm{c}$ & $1.2 \pm 3.3 \mathrm{a}$ & $0.0 \pm 0.0 \mathrm{a}$ & $3.3 \pm 96.7 \mathrm{~b}$ & 80 \\
\hline $0 \mathrm{c}$ & $0.9 \pm 1.3 \mathrm{a}$ & $0.0 \pm 0.0 \mathrm{a}$ & $3.3 \pm 98.7 \mathrm{~b}$ & 90 \\
\hline $0 \mathrm{c}$ & $0.0 \pm 0.0 \mathrm{a}$ & $0.0 \pm 0.0 \mathrm{a}$ & $0.0 \pm 100.0 \mathrm{a}$ & 100 \\
\hline $0 \mathrm{c}$ & $0.0 \pm 0.0 \mathrm{a}$ & $0.0 \pm 0.0 \mathrm{a}$ & $0.0 \pm 100.0 \mathrm{a}$ & 110 \\
\hline $0 \mathrm{c}$ & $0.0 \pm 0.0 \mathrm{a}$ & $0.0 \pm 0.0 \mathrm{a}$ & $0.0 \pm 100.0 \mathrm{a}$ & 120 \\
\hline
\end{tabular}

• الحروف المتثابهة ضمن العمود الواحد تلدل على عدم وجود فــروق معنويــة احصــائية بـين

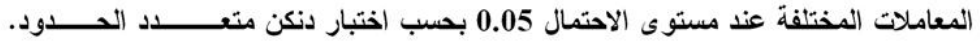


جدول (3) تاثير اشعة كاما في تطور الطور اليرقي الاخير لحشرة ثاقبة الحبوب الصغرى الى بالغات "

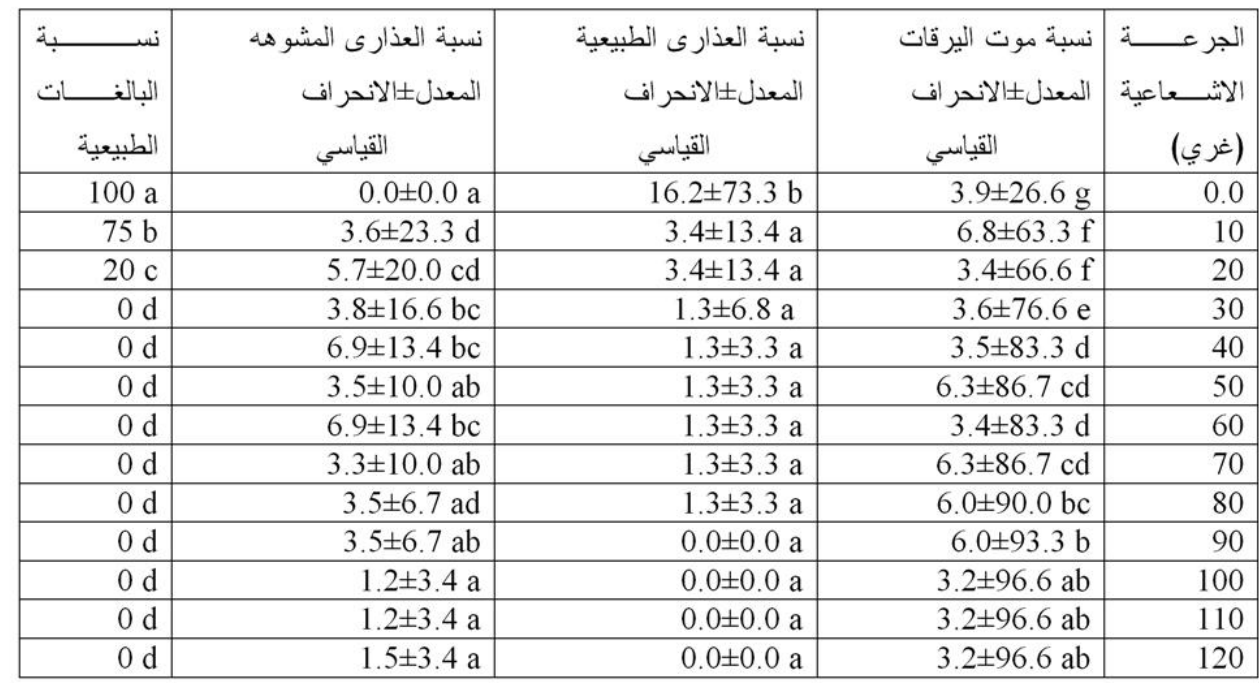

• الحروف المتثابهة ضمن العمود المواحد تلال على عدم وجود فــروق معنويسـة احصــائية بـين

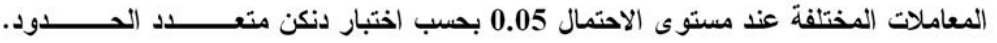

جذول (4) تاثير اثعة كاما في تطور عذارى حشرة ثاقبة الحبوب الصغرى الى بالغات *

\begin{tabular}{|c|c|c|c|}
\hline نسبة البالغات المشو هد & نسبة البالغات الطبيعية & نسبة العذارى الميتك & (غري) الجرعة الاشعاعية \\
\hline $0.0 \pm 3.3 \mathrm{~b}$ & $3.3 \pm 93.3 \mathrm{a}$ & $1.3 \pm 3.4 \mathrm{~d}$ & 0.0 \\
\hline $1.0 \pm 10.0 \mathrm{ab}$ & $3.3 \pm 83.3 \mathrm{a}$ & $3.6 \pm 6.7 \mathrm{~d}$ & 20 \\
\hline $8.8 \pm 13.3 \mathrm{a}$ & $6.7 \pm 76.6 \mathrm{~b}$ & $6.0 \pm 10.0 \mathrm{~cd}$ & 40 \\
\hline $6.6 \pm 23.3 \mathrm{a}$ & $9.8 \pm 53.3 \mathrm{c}$ & $13.3 \pm 23.7 \mathrm{bc}$ & 60 \\
\hline $10.0 \pm 23.3 \mathrm{a}$ & $6.7 \pm 43.3 \mathrm{c}$ & $12.0 \pm 33.3 \mathrm{bc}$ & 80 \\
\hline $5.8 \pm 20.0 \mathrm{a}$ & $3.3 \pm 53.3 \mathrm{c}$ & $6.7 \pm 26.6 \mathrm{bc}$ & 100 \\
\hline $3.4 \pm 26.7 \mathrm{a}$ & $8.8 \pm 36.6 \mathrm{~d}$ & $8.8 \pm 36.6 \mathrm{~b}$ & 120 \\
\hline $3.5 \pm 23.3 \mathrm{a}$ & $6.9 \pm 33.3 \mathrm{~d}$ & $6.6 \pm 43.3 \mathrm{a}$ & 140 \\
\hline $5.7 \pm 20.0 \mathrm{a}$ & $3.3 \pm 23.3 \mathrm{de}$ & $3.3 \pm 66.6 \mathrm{a}$ & 160 \\
\hline $3.3 \pm 13.4 \mathrm{a}$ & $8.8 \pm 13.3$ ef & $6.0 \pm 73.4 \mathrm{a}$ & 180 \\
\hline $5.6 \pm 10.0 \mathrm{ab}$ & $1.3 \pm 3.3 \mathrm{f}$ & $3.3 \pm 86.7 \mathrm{a}$ & 200 \\
\hline
\end{tabular}

الحروف المتثابهة ضمن العمود الواحد تدل على عدم وجود فروق معنوية احصائية بين المعساملات

المختلفة عند مستوى الاحتمال 0.05 بحسب اختبار دنكن متعدد الحدود 
sterile insect \& related nuclear \& other techniques. 9-13/5/2005, ienna, Austeria. Book of Extended Synopses pp. 355

8. Rechcigl, J.E. \& Rechcigl, N.A 2000 Insect pest management techniques for environmental protection. Lewis Publishers, Boca Roton, New york, Washington, D.C., PP. 392.

9. الثريفي ، اخلاص محمد علـي 2004 ، "

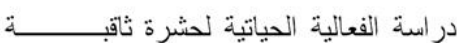

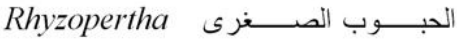

domimica

ومستخلصات بعض النباتـات البقوليــة ".

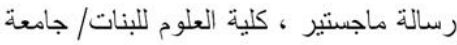

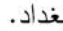

10. AECL, 1984 " Certificate of measurement gamma cell-220 source No.-346, quality control commercial product, Ottawa, Canada.

11. Sas Institute, 2001. SAS Guide for personal computer, version, ed. SAS Institute Inc., Gary, NC. USA.

12. Tilton, E.W.; Brower, J.H.; \& Cogburn, R.R. 1987" Irradiation disinfestations of cormmeal. $\mathrm{J}$. Econ. Entomol., 71(4): 701-703.

13. Bhuiya, A.D.; Ahmed, M.; Rezaur, R.; Nahar,G.; Huda,S.M. S. \& Hossain, S.A.K. 1991. "Radiation disinfestations of pluses, oilseeds \& tobacco leaves". (Insect disinfestations of food \& agricultural products by irradiation), Proc. of the final research coordination meeting, Beijing, China, 25-29/5/1987, PP. 27-50.

14. Ghogomu, T.R. 1990 "Gamma radiation effect on the development of the cowpea weevil, C. maculatus. Med. Fac. Land Bauww. Rij Ksuniv. Gent., 55 (26): 549-555.

$$
\begin{aligned}
& \text { المصادر } \\
& \text { 1. العزاوي ، عبد الله فليح ومهــدي ، محمــد } \\
& \text { طاهر 1983، حشرات المخــازن ، وزارة }
\end{aligned}
$$

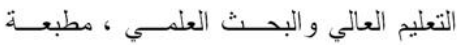

$$
\begin{aligned}
& \text { جامعة الموصل. } \\
& \text { 2. المنظمة العربية للنتمية الزر اعيـــ } 1995 \text { " }
\end{aligned}
$$

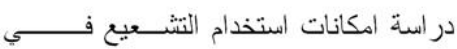

$$
\begin{aligned}
& \text { حفظ وتخزين المنتجات الغذائيــة بـالوطن }
\end{aligned}
$$

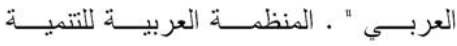

$$
\begin{aligned}
& \text { الزراعيـة الخرطـوم / الســودان. } 281 \\
& \text { صفدة. } \\
& \text { 3. منصور ، محمد } 1997 \text { " مكافحة حشــرات }
\end{aligned}
$$

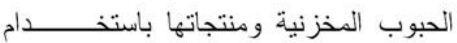

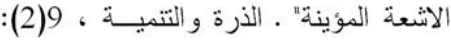

$$
\begin{aligned}
& \text {.35-31 }
\end{aligned}
$$

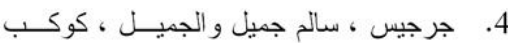

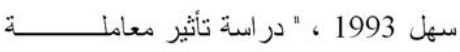

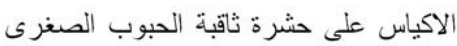

$$
\begin{aligned}
& \text { ونسبة انبات بذور البذرة المخزونــــــــة. } \\
& \text { مجلة زر اعة الر افـدين ، 25(2) : 147- بدرة } \\
& .152 \\
& \text { 5. احمــد ، محمـــد سـعيد هاثـــ } 1998 \text { ، }
\end{aligned}
$$

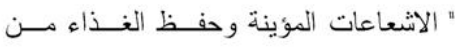

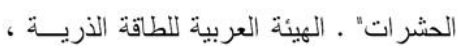

$$
\begin{aligned}
& \text { تونس . } 143 \text { صفحة. } \\
& \text { 6. الهيئة العربيـة للطاقــة الذريـــ } 1995 \text { ، }
\end{aligned}
$$

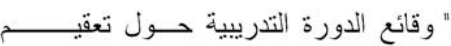

$$
\begin{aligned}
& \text { وحفظ المواد الغذائية بالاشعاع " . الهيئــة } \\
& \text { العربية للطاقــة الذريــة ، تـــونس . } 237 \\
& \text { صفحـة. }
\end{aligned}
$$

7. Follett, P.A. 2005 " Post-harvest irradiation treatments: generic dose, high dose and less than probit9". FAO/IAEA International conference on area-wide control of insect pest: Integrating the 
Callosobruchus maculatus

فترة الخـزن. رســالة ماجسـتير ، كليـة

$$
\text { الزر اعة/جامعة بغداد. }
$$

20. Abdel-kawy, F.K., 1999 " Effect of gamma irradiation on some biological activities of the larval stage of the khapra beetle Trogoderma granarium everts (Coleoptera: Dermestidae). J. of Applied Entomology, 123(4): 201-204.

21. الجواري ، سحر عبد خضــير 2001 ،

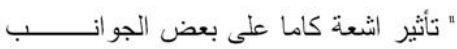

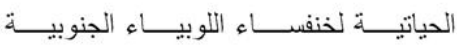

Callosobruchus maculatus

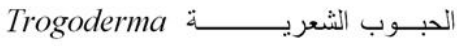

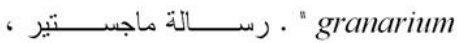

كليــــــة التربية للبنات/جامعة بغداد.

22. Davies, D.R. \& Evans, H.J. 1966 " The role of genetic damage in radiation induced lethality. " In advance in radiation biology, Academic Press, New york \& London. 2: 243-253.

15. Rosada, J..; Nijak, K; \& Weymann, P., 1991 Radiation disinfestations of wheat grain infested by rice weevil $S$. oryzae \& corn weevil $S$. zeamaysi (Coleoptera: Curculionidae). Panstwowe wydawnic two rainicze lesue. PP. 263-267.

16. Diop, Y.M.; Marchioni, E.; Ba, D. \& Hasselmann, C. 1997 "Radiation disinfestations of cowpea seeds contaminated by $C$. maculatus". J. food Process. Preserv., 21(1): 69-81.

17. Shokoohian, A. 1977 "The effect of gamma radiation on different development stages of $D$.maculates ( Coleoptera: Dermestidae ). J. Stored Prod. Res., 13(1): 89-90.

18. Bagheri, Z.E., 1980 "Effect of gamma rays on Callosobruchus maculatus". Faculty of Agriculture, Tehran University, Iran. 513-517.

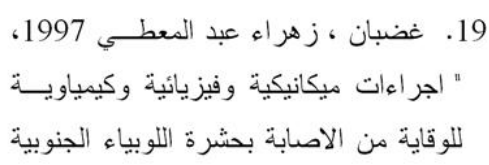




\title{
Effect of Gamma Rays on Some Stages of Development of Rhyzopertha dominica (Fab.)
}

\author{
Aiad A.Al-Taweel * Ikhlas M.Al-Sharifi ** Emad A.Mahmood ** \\ *Directorate of Agric. Res. \& Food Tech., MoST, P.O.Box 765, Baghdad/Iraq. \\ ** College of Science for Women/Baghdad University, Jadriya, Baghdad/Iraq.
}

\begin{abstract}
The effect of different doses of gamma rays that emitted from ${ }^{60} \mathrm{Co}$ on the development of different stages of lesser grain borer Rhyzopertha dominica (Fab.) was investigated. The results showed that the eggs in both early (1-3 days) and late (7-9) old were very sensitive to gamma rays and its hatch was zero at 10 Gy for both ages in comparison with $83.3 \%$ for the control group. Furthermore, the results illustrated that the larval stage in its two old ages were different in the radiosensitivity, the percent of its death were $100 \% \& 96.6 \%$ when they exposed to $100 \& 120 \mathrm{~Gy}$, respectively. Moreover, the results showed that the sensitivity of pupal stage at age of 1-3 days was increased with increasing the doses of gamma rays, the percent of normal adults eclosed from irradiated pupae was $83.3 \%$ at the dose of 20 Gy and it became $3.3 \%$ at the dose of $200 \mathrm{~Gy}$ in comparison with that of the control treatment which was $93.3 \%$.
\end{abstract}

Key Words: Gamma Rays, Lesser grain borer, Biology.

This article is a part from M.Sc. Thesis for the second auther. 